\title{
A Generalized Space Vector Modulation for Cascaded H-Bridge Inverters under Faulty Conditions
}

\author{
Mai Van Chung ${ }^{1,2}$, Truong Viet Hoang ${ }^{1}$, Nguyen Van Cao ${ }^{1}$, Nguyen Manh Linh $^{1 *}$ \\ Vu Hoang Phuong', Nguyen Van Lien ${ }^{1}$ \\ ${ }^{1}$ Hanoi University of Science and Technology, Hanoi, Vietnam \\ ${ }^{2}$ Hung Vuong University, Phutho, Vietnam \\ *Email: linh.nguyenmanh@hust.edu.vn
}

\begin{abstract}
In this research, a new space vector modulation control algorithm is proposed to increase the reliability and the accuracy of the cascaded H-bridge multilevel inverters in case of faulty situations where one or several power cells do not function. When one or more switches of a cell are opened or shorted, that cell is considered faulty. By giving a detailed analysis on the impact of the faulty power cells on the voltage space vectors, the inapplicable voltage vectors are removed precisely. Consequently, the optimal redundant switching states are chosen such that the highest possible output voltage can be achieved. In addition, the balance of the three phases line-to-line voltage and current are maintained. The proposed algorithm is also generalized so that it can be applied to any level of $\mathrm{H}$-bridge inverters. The validity of the method is verified by numerical simulations using MATLAB Simulink with an 11-level cascaded H-bridge inverter.
\end{abstract}

Keywords: Cascaded H-bridge inverter; space vector modulation (SVM); fault tolerant operation of $\mathrm{CHB}$ multilevel inverters

\section{Introduction}

Multi-level inverters have been widely used in industrial applications with high voltage range, large capacity due to following advantages: lower total harmonics distortion (THD) at output current/voltage waveform, lower voltage drop and stress on power switches, low $d v / d t$ and high reliability since the faulty module can be bypass in several particular situation $[1,2] \ldots$ The topology of cascaded H-bridge multilevel inverter $(\mathrm{CHB})$ is described in detail in [3-8]. In comparison with the diode - clamped topology, CHBbased inverter is more popular in industry due to its high modularization, as well as its ability to use the redundancy voltage vectors to solve the multiobjective optimization problem [9].

With a large number of power switches and complicated topology, modulation strategy for multilevel inverters is a challenge, especially when the number of levels is high. Among all modulation strategies, the space vector modulation (SVM), which has been widely used for conventional 3-phase inverters, can also be applied to CHB topology with the superior performance although high computational cost is required. By using SVM, the multipleobjectives problems such as: switching state optimization, load-source neutral voltage minimization, capacitor voltage balance, phase voltage balance can be implemented thoroughly by utilizing redundancy voltage vector [10-15]. Recently, thanks to the generalized SVM algorithm [16-20], the implementation of SVM for H-bridge inverter with any number of levels on digital control platform has become much easier.

As the number of levels is increased, e.g., in medium and high voltage applications, the possibility of malfunction caused by faulty power switches is unavoidable [9]. Normally, the inverter is disconnected from the line/load by the protection system, resulting in a sudden stop of motors which may cause other serious problems, e.g., water hammer in pump system. Besides, if the inverter continues to work under faulty conditions, the output voltage can be unbalanced, leading to motor failure after operating for a long period of time. Therefore, modulation strategy in faulty conditions to maintain proper operation of the inverter is a challenging issue.

The "bypass cell" method which bypasses the cell that contains the faulty switches is suggested in [21]. This method is quite simple, easy to implement, and can generate balance voltage between phases. However, the corresponding cells in the other phases must also be removed, leading to the reduction of the output voltage. To overcome this drawback, the neutral point shifting method has been proposed $[22,23]$, in which, only the faulty cell is removed. As a result, the output voltage is usually larger than "bypass cell" method. Space vector modulation technique is also proposed in [24] and has the same performance as

ISSN: 2734-9373

https://doi.org/10.51316/jst.152.ssad.2021.31.2.12

Received: January 16, 2020; accepted: June 25, 2020 
the neutral point shifting method. However, both methods are complicated, especially when the number of levels increases. Therefore, most researches are only based on inverters with limited levels.

In this research, an improvement of the generalized SVM method for the cascaded H-bridge multilevel inverter under faulty conditions is proposed. The proposed method guarantees that multipleobjectives such as: switching loss optimization, maximum output voltage, and output phase voltage balance can be achieved.

\section{An Analysis on CHB under Fault Condition and Power Circuit Reconfiguration Method}

\subsection{CHB structure with bypass switches}

The typical configuration of a CHB inverter with bypass switches is shown in Fig. 1. Each power module is called a cell. And the CHB inverter is formed by connecting multiple cells in cascade for each phase. Since each cell is equipped with a bypass switch, the faulty cells can be removed as illustrated in Fig. 2 .

\subsection{Output Voltage Effects under Fault}

According to [5], the output voltage vectors of the CHB is arranged as shown in Fig. 3. When an error occurs, some switching combination is not possible because the relevant power cell is removed. The lack of switching combination makes some voltage vectors cannot be implemented, forming a layer of faulty space voltage vectors.

Fig. 4 depicts some typical examples of space vectors when one or more cells of the CHB is fail. The triangles represent the faulty vector that is unusable for the modulation. The position of faulty space vectors is summarized in Table 1. It can be seen that when a cell in phase A corrupted, some space vectors in sectors I, III, IV, and VI are affected, while the vectors in sectors II and $\mathrm{V}$ are not affected.

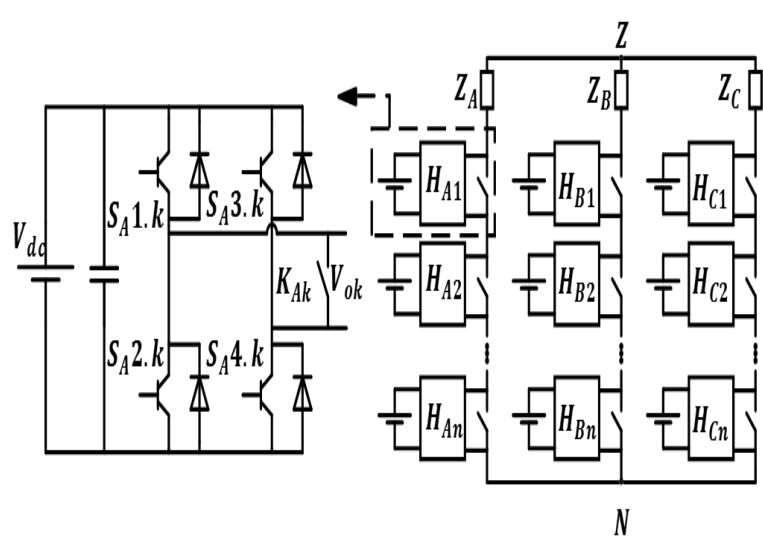

a)

b)

Fig. 1. a. CHB with bypass switches. b. A cell in detail

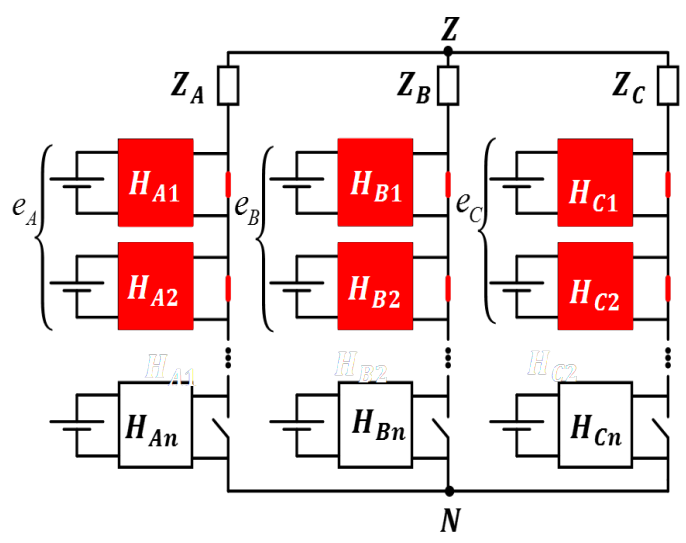

Fig. 2. Inverter when errors occur.

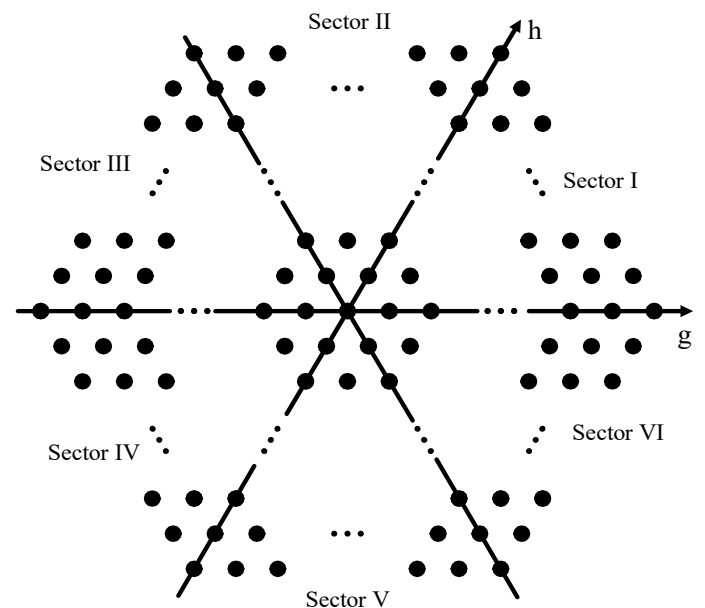

Fig. 3. Voltage space vectors of CHB with $M$ levels.

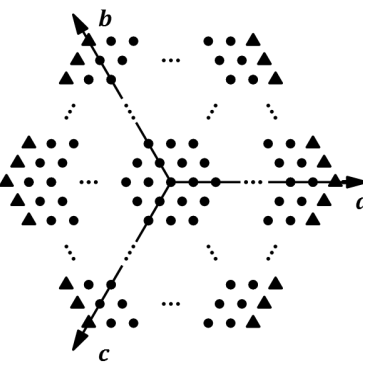

a)

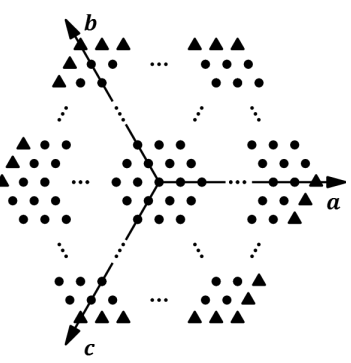

b)

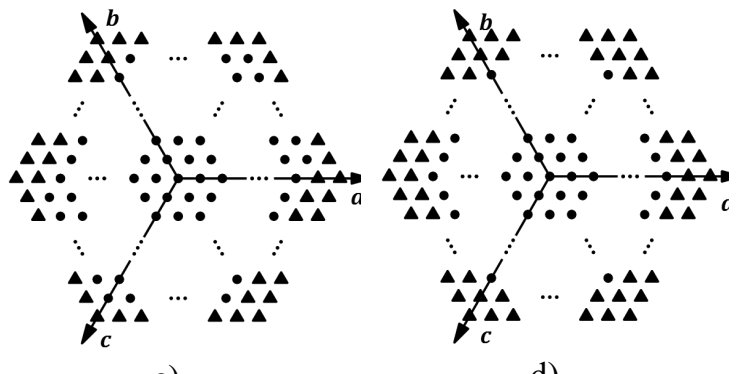

c)

d)

Fig. 4. The effects of output voltage vectors under faulty conditions. (a) Output voltage vectors when cell A1 is faulty. (b) Output voltage vectors when cell B1 is faulty. (c) Output voltage vectors when cell A1 and B1 are faulty. (d) Output voltage vectors when cell A1, $\mathrm{B} 1$ and $\mathrm{C} 1$ are faulty. 
Table 1. Location of space vectors affected by faulty cells.

\begin{tabular}{cccc}
\hline $\begin{array}{c}\text { Sector } \\
\text { affected }\end{array}$ & \multicolumn{3}{c}{$\begin{array}{c}\text { Inverter phases with faulty } \\
\text { power cells }\end{array}$} \\
& Phase A & Phase B & Phase C \\
\hline I & Yes & No & Yes \\
II & No & Yes & Yes \\
III & Yes & Yes & No \\
IV & Yes & No & Yes \\
V & No & Yes & Yes \\
VI & Yes & Yes & No \\
\hline
\end{tabular}

\section{SVM Method for CHB with any Level Under} Faulty Conditions.

To ensure that the CHB operates properly despite the existence of a faulty power cell, an improvement of the generalized SVM method [5] is proposed, which consists of the following steps:

- Calculating new reference voltage

- Locating the reference voltage

- Determining the modulation period

- Determining the switching state

- Specifying optimized switching order, switching combination of the switches.

In comparison with [5], step 1 and step 4 need to be modified because of the influence of faulty cells. The remaining steps are preserved. Therefore, this paper only focuses on step 1 and step 4 .

\subsection{Calculating New Reference Voltage}

When faulty power cells occur, some unachievable switching combinations are formed, creating a group of faulty voltage vectors. At this point, creating desired output voltage vectors may not be available if faulty vectors are used in the modulation algorithm. Therefore, the purpose of this section is to determine the number of defective layers, the maximum voltage value that can be modulated, thereby calculating the value of new reference voltage.

Number of faulty space voltage vector layers per sector is obtained by equation (1).

$$
\left\{\begin{array}{l}
e_{I}=e_{A}+e_{C} \\
e_{I I}=e_{B}+e_{C} \\
e_{I I I}=e_{A}+e_{B} \\
e_{I V}=e_{A}+e_{C} \\
e_{V}=e_{B}+e_{C} \\
e_{V I}=e_{A}+e_{B}
\end{array}\right.
$$

where $e_{I \ldots V I}$ are the number of faulty vector layers of sector I...VI.

The maximum number of faulty vector layers in vector space is determined as:

$$
e_{\max }=\max \left(\mathrm{e}_{A}+e_{B} ; \mathrm{e}_{A}+e_{C} ; \mathrm{e}_{B}+e_{C}\right)
$$

The maximum possible amplitude of reference voltage corresponds to the radius of the inscribed circle of the largest hexagon which is not affected by the faulty vectors, as illustrated in Fig. 5:

$$
v_{\text {max }}^{\prime}=\frac{1}{\sqrt{3}} V_{d c}\left(M-1-e_{\max }\right)
$$

where $M$ is the level of the CHB.

After determining $v_{\max }^{\prime}$, the new reference voltage $v_{\text {ref }}$ ' can be obtained by the algorithm in Fig. 6 .

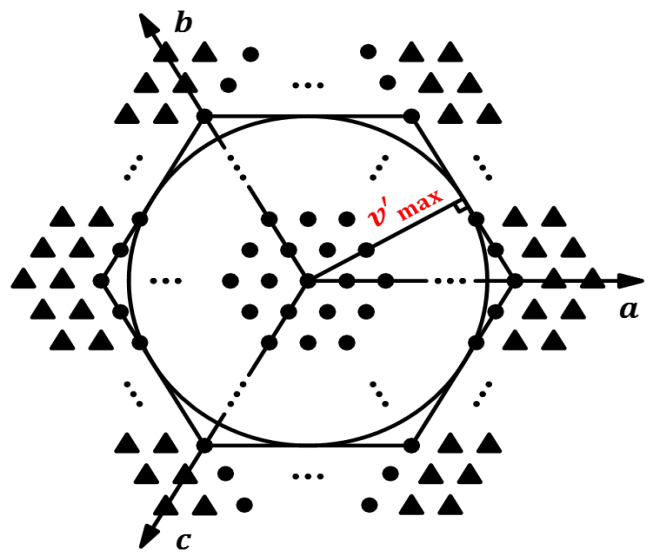

Fig. 5. Calculating the maximum voltage vector can be achieved in faulty $\mathrm{CHB}$.

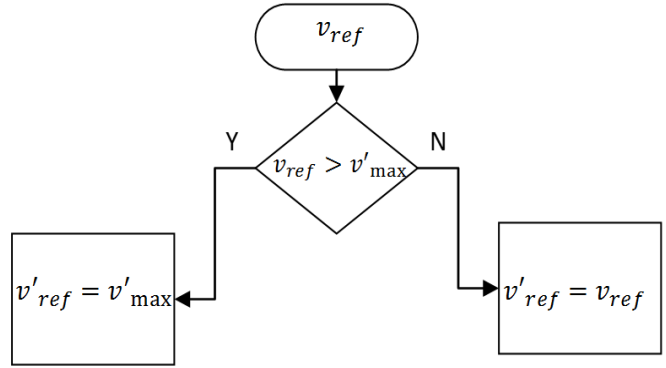

Fig. 6. Alogrithm flowchart for determining reference voltage $v_{r e f}$ under faulty conditions.

\subsection{Determining Switching States in Faulty Conditions}

When there are $e_{A}, e_{B}, e_{C}$ faulty cells on phase A, $\mathrm{B}$ and $\mathrm{C}$, repectively, the converter needs to be reconstructed by shorting these faulty cells. Thereby, the voltages can be created as follows:

$$
\left\{\begin{array}{l}
V_{A N}=k_{A N} \cdot V_{d c} \\
V_{B N}=k_{B N} \cdot V_{d c} \\
V_{C N}=k_{C N} \cdot V_{d c}
\end{array}\right.
$$


Table 2. Specifying level of phases and $k$ selection in sectors $\left(k_{0}=k_{g}+k_{h}\right)$

\begin{tabular}{|c|c|c|c|c|c|c|}
\hline \multicolumn{7}{|c|}{ Sector } \\
\hline & $\mathrm{I}$ & II & III & IV & $\mathrm{V}$ & VI \\
\hline$\left[\begin{array}{l}k_{g} \\
k_{h}\end{array}\right]$ & {$\left[\begin{array}{l}k_{A N}-k_{B N} \\
k_{B N}-k_{C N}\end{array}\right]$} & {$\left[\begin{array}{l}k_{A N}-k_{C N} \\
k_{B N}-k_{A N}\end{array}\right]$} & {$\left[\begin{array}{l}k_{B N}-k_{C N} \\
k_{C N}-k_{A N}\end{array}\right]$} & {$\left[\begin{array}{c}k_{B N}-k_{A N} \\
k_{C N}-k_{B N}\end{array}\right]$} & {$\left[\begin{array}{l}k_{C N}-k_{A N} \\
k_{A N}-k_{B N}\end{array}\right]$} & {$\left[\begin{array}{l}k_{C N}-k_{B N} \\
k_{A N}-k_{C N}\end{array}\right]$} \\
\hline $\left.\begin{array}{l}k_{A N} \\
k_{B N} \\
k_{C N}\end{array}\right]$ & {$\left[\begin{array}{c}k \\
k-k_{g} \\
k-k_{g}-k_{h}\end{array}\right]$} & {$\left[\begin{array}{c}k-k_{h} \\
k \\
k-k_{g}-k_{h}\end{array}\right.$} & {$\left[\begin{array}{c}k-k_{g}-k_{h} \\
k \\
k-k_{g}\end{array}\right]$} & {$\left[\begin{array}{c}k-k_{g}-k_{h} \\
k-k_{h} \\
k\end{array}\right]$} & {$\left[\begin{array}{c}k-k_{g} \\
k-k_{g}-k_{h} \\
k\end{array}\right]$} & {$\left[\begin{array}{c}k \\
k-k_{g}-k_{h} \\
k-k_{h}\end{array}\right]$} \\
\hline$k$ & $\left.\begin{array}{c}\max \\
-n+e_{A} \\
-n+k_{g}+e_{B} \\
-n+k_{0}+e_{C}\end{array}\right]$ & $\begin{array}{c}\max \\
{\left[\begin{array}{c}-n+k_{h}+e_{A} \\
-n+e_{B} \\
-n+k_{0}+e_{C}\end{array}\right]}\end{array}$ & $\begin{array}{c}\max \\
{\left[\begin{array}{c}-n+k_{0}+e_{A} \\
-n+e_{B} \\
-n+k_{g}+e_{C}\end{array}\right]}\end{array}$ & $\begin{array}{c}\max \\
{\left[\begin{array}{c}-n+k_{0}+e_{A} \\
-n+k_{h}+e_{B} \\
-n+e_{C}\end{array}\right]}\end{array}$ & $\begin{array}{c}\max \\
{\left[\begin{array}{c}-n+k_{g}+e_{A} \\
-n+k_{0}+e_{B} \\
-n+e_{C}\end{array}\right]}\end{array}$ & $\left.\begin{array}{c}\max \\
-n+e_{A} \\
-n+k_{0}+e_{B} \\
-n+k_{h}+e_{C}\end{array}\right]$ \\
\hline
\end{tabular}

Table 3. Coordinates of voltage vectors in sector I.

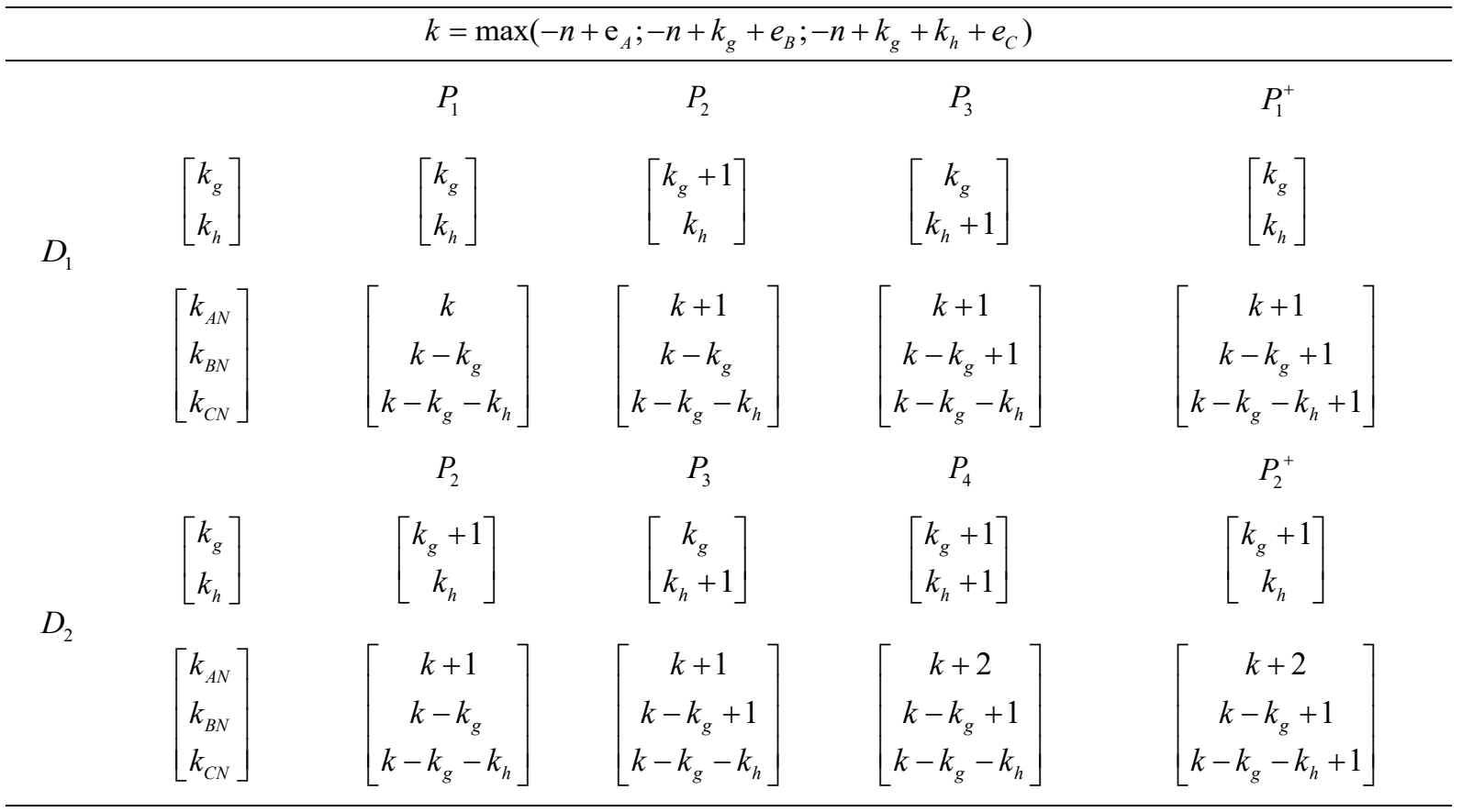

where:

$$
\left\{\begin{array}{l}
k_{A N} \in \overline{-n+e_{A} ; \mathrm{n}-\mathrm{e}_{A}} \\
k_{B N} \in \overline{-n+e_{B} ; \mathrm{n}-\mathrm{e}_{B}} \\
k_{C N} \in \overline{-n+e_{C} ; \mathrm{n}-\mathrm{e}_{C}}
\end{array}\right.
$$

To determine the switching combinations that generate unfaulty voltage vector on vector space, steps can be done as following.

With sector I: Consider a voltage vector which has the coordinates $\left[v_{g} ; v_{h}\right]$ illustrated in Fig. 7. This voltage vector can be represented by the equations (6) as follows:

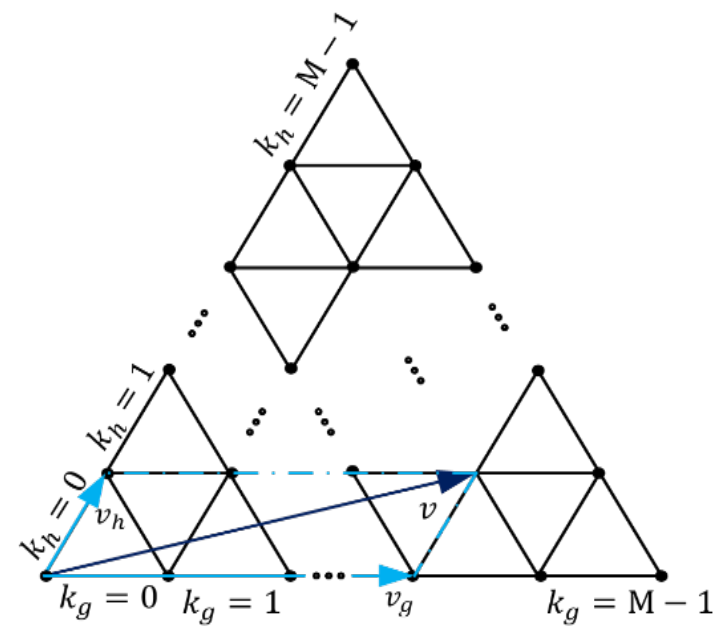

Fig.7. A sector I voltage vector representation. 


$$
\left\{\begin{array}{l}
v_{g}=\frac{2}{3} V_{d c} k_{g}=\frac{2}{3} V_{d c}\left(k_{A N}-k_{B N}\right) \\
v_{h}=\frac{2}{3} V_{d c} k_{h}=\frac{2}{3} V_{d c}\left(k_{B N}-k_{C N}\right)
\end{array}\right.
$$

From (6), we can write:

$$
\left[\begin{array}{l}
k_{g} \\
k_{h}
\end{array}\right]=\left[\begin{array}{l}
\left(k_{A N}-k_{B N}\right) \\
\left(k_{B N}-k_{C N}\right)
\end{array}\right]
$$

with $k_{A}=k$, (7) can be rewritten on abc coordinate:

$$
\left[\begin{array}{c}
k_{g} \\
k_{h}
\end{array}\right] \Rightarrow\left[\begin{array}{c}
k_{A N} \\
k_{B N} \\
k_{C N}
\end{array}\right]=\left[\begin{array}{c}
k \\
k-k_{g} \\
k-k_{g}-k_{h}
\end{array}\right]
$$

However, these coordinates must satisfy (5), as (9):

$$
\left\{\begin{array}{l}
-n+e_{A} \leq k \leq n-e_{A} \\
-n+e_{B} \leq k-k_{g} \leq n-e_{B} \\
-n+e_{C} \leq k-k_{g}-k_{h} \leq n-e_{C}
\end{array}\right.
$$

From (9), (10) is given:

$$
\left\{\begin{array}{l}
-n+e_{A} \leq k \leq n-e_{A} \\
-n+k_{g}+e_{B} \leq k \leq n+k_{g}-e_{B} \\
-n+k_{g}+k_{h}+e_{C} \leq k \leq n+k_{g}+k_{h}-e_{C}
\end{array}\right.
$$

That means $k$ must satisfy (11):

$$
\max \left\{\begin{array}{c}
-n+e_{A} \\
-n+k_{g}+e_{B} \\
-n+k_{g}+k_{h}+e_{C}
\end{array}\right\} \leq k \leq \min \left\{\begin{array}{c}
n-e_{A} \\
n+k_{g}-e_{B} \\
n+k_{g}+k_{h}-e_{C}
\end{array}\right\}
$$

In other sectors, the states can be determined exactly same way as above, by replacing $\left[\begin{array}{c}k_{\mathrm{g}} \\ k_{\mathrm{h}}\end{array}\right]$ in sector I by respective coordinates of these sectors, which are summarized in Table 2.

By implementing the optimized switching algorithm applied for faulty cell conditions, the result can be achieved in Table 3.

\section{Simulation Results}

To verify the correctness and effectiveness of the proposed method, simulation on Matlab - Simulink software is implemented. Specifically, the algorithm is applied to 11-level CHB inverter, the DC voltage on each cell $U_{D C}=60 \mathrm{~V}$, reference voltage $U_{A}=330 \sin \omega t$, the phases are balance as the phase angles difference are $120^{\circ}$. Faulty cells are assumed as shown in Table 4. Error is generated by making a switch of the faulty cell open, other switches keep operating normally.
Table 4. Error assumption in 11-level CHB.

\begin{tabular}{cccc}
\hline & \multicolumn{3}{c}{ Pha xảy ra lỗi } \\
\hline Thời gian (s) & $\mathrm{A}$ & $\mathrm{B}$ & $\mathrm{C}$ \\
$0-0,05$ & 0 & 0 & 0 \\
$0,05-0,1$ & $H_{A 1}$ & 0 & 0 \\
$0,1-0,15$ & $H_{A 1}$ & $H_{\mathbf{B} 1} ; H_{B 3}$ & $H_{C 1} ; H_{C 3} ; H_{C 5}$
\end{tabular}

Simulation results:

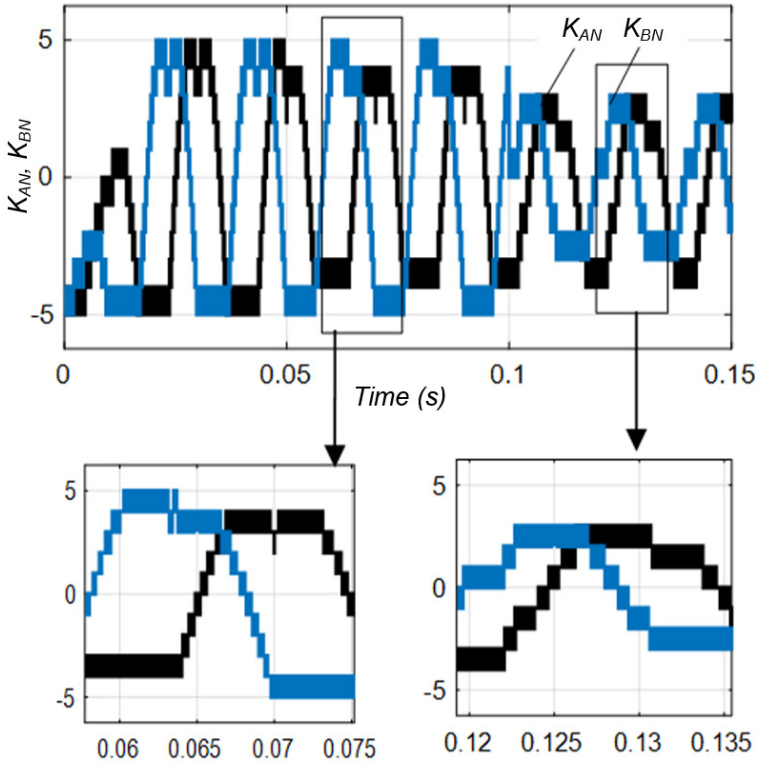

Fig. 8. Level state on phase A and phase B with error handling algorithm.

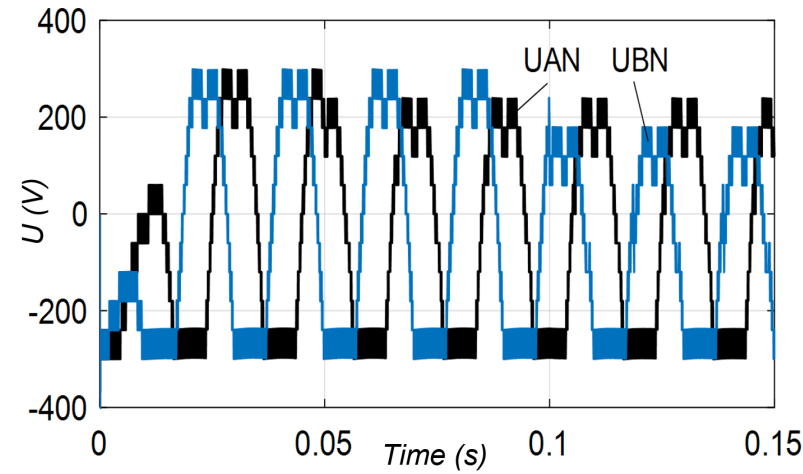

Fig. 9. Output voltage on phases: $U_{A N}$ and $U_{B N}$ without error handling algorithm.

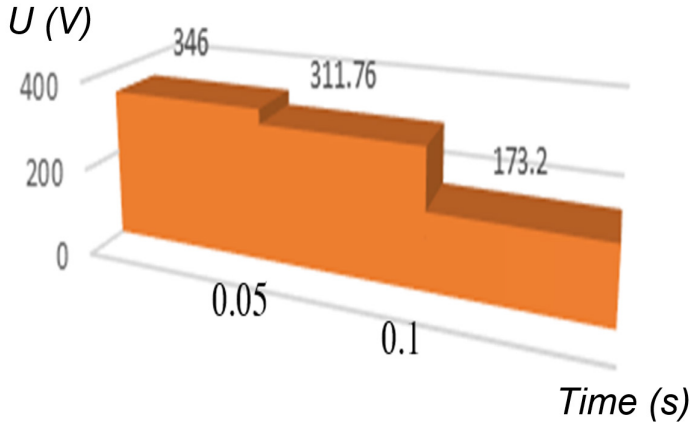

Fig. 10. Maximum output voltage of $\mathrm{CHB}$ under faulty conditions. 


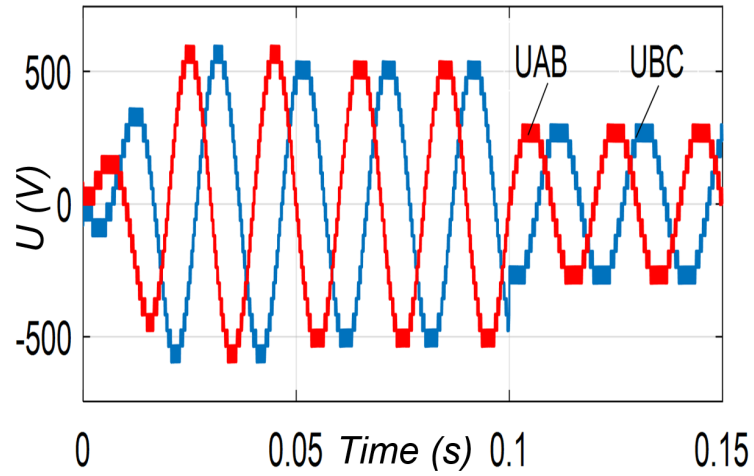

Fig. 11. Line voltage waveform: $U_{A B}$ and $U_{B C}$ with error handling algorithm.

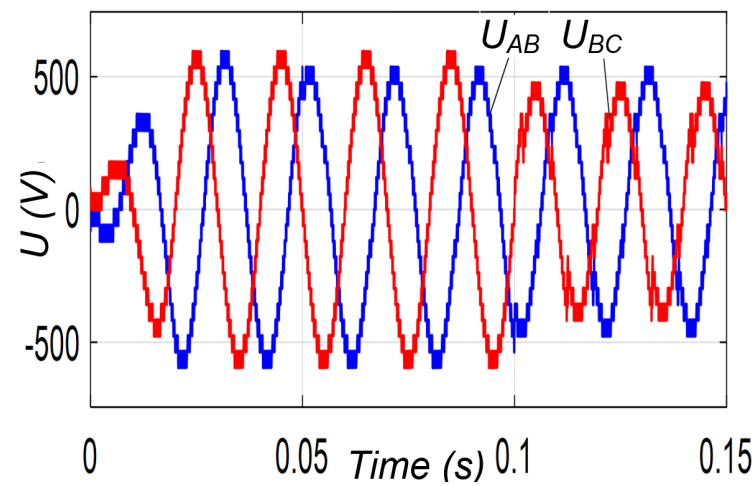

Fig. 12. Line voltage waveform: $U_{A B}$ and $U_{B C}$ without error handling algorithm.

In terms of phase output voltage, we can clearly see as Fig. 8, when phase A fails between $0.05-0.1 \mathrm{~s}$, the error handling algorithm removed the $-5,5$ level of the A-phase voltage corresponds to 1 faulty power cell. Similarly, with phase B, for the period from 0.01 to $0.15 \mathrm{~s}$, levels $-5,-4,4,5$ have been removed, corresponds to 2 faulty cells. When there is no error handling algorithm, the modulated voltage waveform $U_{A N}, U_{B N}, U_{C N}$ depicted in Fig. 9 from 0 to 0.05 seconds. However, the real voltage on phase has lost a level with 1 faulty power cell, which causes the output voltage to be unbalanced as shown in Fig 9.

Fig. 10 shows that with the error handling algorithm, the output voltage has the smallest drop. Specifically, in the time interval from $0.05 \mathrm{~s}-0.1 \mathrm{~s}$ there is 1 layer of faulty space voltage vectors, maximum output voltage compared to normal condition is $90 \%$. There are 5 faulty layers from $0.1 \mathrm{~s}$ to $0.15 \mathrm{~s}$, the output voltage reaches 50\%. Fig. 11 and 13 show that the voltage waveform on the load $U_{A Z}, U_{B Z}, U_{C Z}$ and line voltage $U_{A B}, U_{B C}$ are perfectly balanced when an error occurs.

When the algorithm for error handling is not implemented, if an error occurs, the output voltage of the inverter will be unbalanced as shown in Figure 12, 14. Particularly, with short circuit power switches error, DC power supply is short-circuited, causing

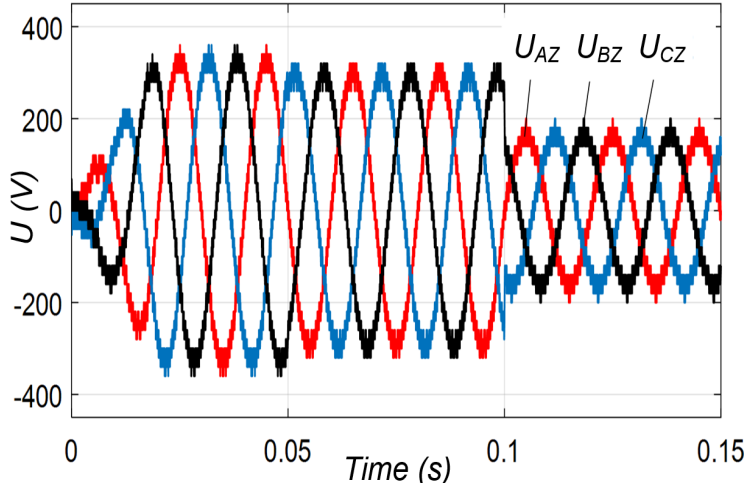

Fig. 13. Output voltage on load: $U_{A z} ; U_{B z} ; U_{C z}$ with error handling algorithm.

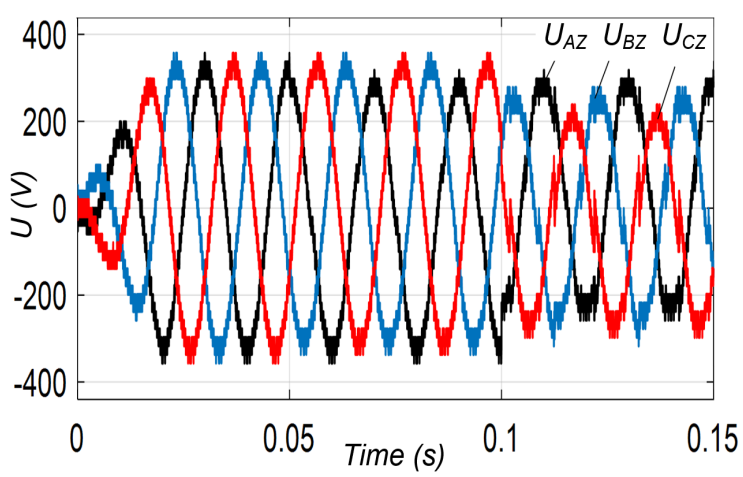

Fig. 14. Output voltage on load: $\mathrm{U}_{\mathrm{Az}} ; \mathrm{U}_{\mathrm{Bz}} ; \mathrm{U}_{\mathrm{Cz}}$ without error handling algorithm.

danger for the inverter. With the error handling algorithm, by adding auxiliary components and implementing new modulation technique, the inverter could continue to work with both short circuit and open circuit switches errors.

\section{Conclusion and Further Development}

This paper has proposed a space vector modulation method for cascaded $\mathrm{H}$-bridge inverter structure in case of power cell malfunction. The proposed algorithm has achieved the following results. First, the faulty cell is bypassed so that the system can continue to work properly. Second, the output voltage attenuation is minimized in comparison with the "bypass cell" method where cells are bypassed on all three phases. In addition, the given algorithm ensures the balance of three phases. Finally, the proposed method with optimized switching sequence can easily be applied to cascaded H-bridge inverter with arbitrary-levels. The proposed method is verified by numerical simulation using Matlab-Simulink.

\section{Acknowledgments}

This research is funded by the Hanoi University of Science and Technology (HUST) under project number T2018-PC-050. 


\section{References}

[1]. B. Wu, 1. Cascaded H-bridge multilevel inverters 7.1, High-Power Converters and AC Drives. pp. 119-142, 2006.

https://doi.org/10.1002/9780471773719

[2]. R. José et al., Multilevel converters: An enabling technology for high-poer applications, Proceedings of the IEEE, vol. 97, no. 11. pp. 1786-1817, 2009, https://doi: 10.1109/JPROC.2009.2030235.

[3]. J. S. Lai and F. Z. Peng, multilevel converters - A new breed of power converters, IEEE Transactions on Industry Applications, vol. 32, no. 3. pp. 509-517, 1996,

https://doi: 10.1109/28.502161.

[4]. M. Marchesoni, M. Mazzucchelli, and S. Tenconi, A Nonconventional power converter for plasma stabilization, IEEE Transactions on Power Electronics, vol. 5, no. 2. pp. 212-219, 1990, https://doi: $10.1109 / 63.53158$

[5]. S. Kouro et al., Recent advances and industrial applications of multilevel converters, IEEE Transactions on Industrial Electronics, vol. 57, no. 8. pp. 2553-2580, 2010,

https://doi: 10.1109/TIE.2010.2049719.

[6]. E. Villanueva, P. Correa, J. Rodriguez, and M. Pacas, Control of a single-phase cascaded H-bridge multilevel inverter for grid-connected photovoltaic systems, IEEE Trans. Ind. Electron., vol. 56, no. 11, pp. 4399-4406, 2009, https://doi: 10.1109/TIE.2009.2029579.

[7]. J. Sastry, P. Bakas, H. Kim, L. Wang, and A. Marinopoulos, Evaluation of cascaded H-bridge inverter for utility-scale photovoltaic systems, Renew. Energy, vol. 69, pp. 208-218, 2014, https://doi: 10.1016/j.renene.2014.03.049.

[8]. F. Khoucha, S. M. Lagoun, K. Marouani, A. Kheloui, and M. E. H. Benbouzid, Hybrid cascaded H-bridge multilevel-inverter induction-motor-drive direct torque control for automotive applications, IEEE Trans. Ind. Electron., vol. 57, no. 3, pp. 892-899, 2010, https://doi: 10.1109/TIE.2009.2037105.

[9]. B. Hemanth Kumar, M. M. Lokhande, R. R. Karasani, and V. B. Borghate, Fault tolerant operation of CHB multilevel inverters based on the SVM technique using an auxiliary unit, Journal of Power Electronics, vol. 18, no. 1. pp. 56-69, 2018, https://doi: 10.6113/JPE.2018.18.1.56.

[10]. B. P. McGrath, D. G. Holmes, and T. Lipo, Optimized space vector switching Sequences for multilevel inverters, IEEE Trans. Power Electron., vol. 18, no. 6, pp. 1293-1301, 2003, https://doi: 10.1109/TPEL.2003.818827.

[11]. T. Brückner and D. G. Holmes, Optimal pulse-width modulation for three-level inverters, IEEE Trans. Power Electron., vol. 20, no. 1, pp. 82-89, 2005, https://doi: 10.1109/TPEL.2004.839831.

[12]. B. Urmila and D. Subba Rayudu, Optimum space vector PWM algorithm for three-level inverter, J. Eng. Appl. Sci., vol. 6, no. 9, pp. 24-36, 2011.
[13]. S. Choi and M. Saeedifard, Capacitor voltage balancing of flying capacitor multilevel converters by space vector PWM, IEEE Trans. Power Deliv., vol. 27, no. 3, pp. 1154-1161, 2012, https://doi: 10.1109/TPWRD.2012.2191802.

[14]. A. K. Gupta and A. M. Khambadkone, A space vector modulation scheme to reduce common mode voltage for cascaded multilevel inverters, IEEE Trans. Power Electron., vol. 22, no. 5, pp. 1672-1681, 2007, https://doi: 10.1109/TPEL.2007.904195.

[15]. F. Wang, Motor shaft voltages and bearing currents and their reduction in multilevel medium-voltage PWM voltage-source-inverter drive applications, IEEE Trans. Ind. Appl., vol. 36, no. 5, pp. 1336-1341, 2000 , https://doi: 10.1109/28.871282.

[16]. C. M. Van, T. N. Xuan, P. V. Hoang, M. T. Trong, S. P. Cong, and L. N. Van, A Generalized space vector modulation for cascaded h-bridge multi-level inverter, in Proceedings of 2019 International Conference on System Science and Engineering, ICSSE 2019, Sep. 2019, pp. 18-24, https://doi: 10.1109/ICSSE.2019.8823465

[17]. S. Wei, B. Wu, F. Li, and C. Liu, A general space vector PWM control algorithm for multilevel inverters, Conf. Proc. - IEEE Appl. Power Electron. Conf. Expo. - APEC, vol. 1, no. 1, pp. 562-568, 2003, https://doi: 10.1109/apec.2003.1179268.

[18]. Y. Deng, K. H. Teo, C. Duan, T. G. Habetler, and R. G. Harley, A fast and generalized space vector modulation scheme for multilevel inverters, IEEE Transactions on Power Electronics, vol. 29, no. 10. pp. 5204-5217, 2014, https://doi: 10.1109/TPEL.2013.2293734.

[19]. A. K. Gupta and A. M. Khambadkone, A space vector PWM scheme for multilevel inverters based on twolevel space vector PWM, IEEE Trans. Ind. Electron., vol. 53, no. 5, pp. 1631-1639, 2006, https://doi: 10.1109/TIE.2006.881989.

[20]. F. Chen and W. Qiao, A general space vector PWM scheme for multilevel inverters, ECCE 2016 - IEEE Energy Conversion Congress and Exposition, Proceedings. 2016, https://doi: 10.1109/ECCE.2016.7854687.

[21]. P. Correa and J. Rodriguez, Control strategy reconfiguration for a multilevel inverter operating with bypassed cells, IEEE International Symposium on Industrial Electronics. pp. 3162-3167, 2007, https://doi: 10.1109/ISIE.2007.4375121.

[22]. J. Rodríguez et al., Operation of a medium-voltage drive under faulty conditions, IEEE Transactions on Industrial Electronics, vol. 52, no. 4. pp. 1080-1085, 2005.

[23]. M. Aleenejad, H. Mahmoudi, and R. Ahmadi, Unbalanced space vector modulation with fundamental phase shift compensation for faulty multilevel converters, IEEE Transactions on Power Electronics, vol. 31, no. 10. pp. 7224-7233, 2016, https://doi: 10.1109/TPEL.2015.2509446. 
JST: Smart Systems and Devices

Volume 31, Issue 2, September 2021, 092-099

[24]. S. Wei, B. Wu, F. Li, and X. Sun, Control method for cascaded H-bridge multilevel inverter with faulty power cells, Conference Proceedings - IEEE Applied Power Electronics Conference and Exposition - APEC, vol. 1. pp. 261-267, 2003,

https://doi: 10.1109/apec.2003.1179224. 